\title{
PATIENT SAFETY CULTURE IN A TEACHING HOSPITAL: DIFFERENCES IN PERCEPTION EXISTING IN THE DIFFERENT SCENARIOS OF THIS INSTITUTION ${ }^{1}$
}

\author{
Edenise Maria Santos da Silva-Batalha², Marta Maria Melleiro ${ }^{3}$
}

\footnotetext{
${ }^{1}$ Article extracted from the dissertation titled - Patient safety culture in the perception of nursing professionals in a teaching hospital, presented to the School of Nursing of the Universidade de São Paulo (USP), in 2012.

${ }^{2}$ M.Sc. in Nursing Management. Assistant Professor in the Department of Life Sciences of Universidade do Estado da Bahia. Salvador, Bahia, Brazil. E-mail: edenisemaria@gmail.com

${ }^{3}$ Ph.D in Nursing. Associate Professor with the Department of Career Counselling of the School of Nursing, USP. São Paulo, São Paulo, Brazil. E-mail: melleiro@usp.br
}

\begin{abstract}
This quantitative descriptive-exploratory study aimed to evaluate the perception of nursing professionals regarding the patient safety culture and to identify differences in perception in the hospital's units. A total of 301 nursing professionals participated. The collection instrument was the Agency for Healthcare Research and Quality questionnaire, titled 'Hospital Survey on Patient Safety Culture'. Data analysis was undertaken through descriptive and analytical statistics. As a result, it was observed that there were significant differences between the units, emphasis being placed on the pediatric units, which had better perceptions of safety (mean: 3.43 and median: 3.44). These findings make it possible to outline models for quality improvement which are more specific for each department, and the analysis of the contexts makes it possible to build good practices in health which are directed towards each work process performed in the institution.
\end{abstract}

DESCRIPTORS: Quality of health care. Evaluation of health services. Patient safety. Nursing.

\section{CULTURA DE SEGURANÇA DO PACIENTE EM UM HOSPITAL DE ENSINO: DIFERENÇAS DE PERCEPÇÃO EXISTENTES NOS DIFERENTES CENÁRIOS DESSA INSTITUIÇÃO}

RESUMO: Estudo quantitativo descritivo-exploratório que teve como objetivos avaliar a percepção de profissionais de enfermagem acerca da cultura de segurança do paciente e identificar diferenças de percepção nas unidades do hospital. Participaram 301 profissionais de enfermagem. O instrumento de coleta foi o questionário da Agency for Healthcare Research and Quality, intitulado Hospital Survey on Patient Safety Culture. A análise dos dados se deu por estatísticas descritivas e analíticas. Como resultado constatou-se que havia diferenças significativas entre as unidades, destacando-se as unidades pediátricas que tiveram melhores percepções de segurança (média: 3,43 e mediana: 3,44). Esses achados possibilitam traçar modelos de melhoria da qualidade mais específicos para cada setor e a análise dos contextos permite arquitetar boas práticas em saúde direcionadas para cada processo de trabalho desempenhado na instituição.

DESCRITORES: Qualidade da assistência à saúde. Avaliação de serviços de saúde. Segurança do paciente. Enfermagem.

\section{CULTURA DE LA SEGURIDAD DEL PACIENTE EN UN HOSPITAL UNIVERSITARIO: LA PERCEPCIÓN DE PROFESIONALES EN DIFERENTES ESCENARIOS DE ESA INSTITUCIÓN}

\begin{abstract}
RESUMEN: Este estudio cuantitativo tuvo como objetivo evaluar la percepción de las enfermeras sobre la cultura de seguridad del paciente, y para identificar las diferencias en la percepción de las unidades hospitalarias. Participaron de este estudio 301 profesionales de enfermería. El instrumento de recolección de datos fue un cuestionario de la Agencia de Investigación y Calidad de la Salud, entitulado Encuesta Hospitalaria sobre la Cultura de Seguridad de Pacientes. El análisis de datos se realizó mediante estadística descriptiva y analítica. Como resultado se encontró que no había diferencias significativas entre las unidades, especialmente en las unidades pediátricas que tuvieron una mejor percepción sobre la seguridad de los pacientes (media: 3,43 y la mediana: 3,44). Estos resultados hacen posible rastrear modelos más específicos de mejoría de la calidad para cada sector y el análisis de los contextos permitió planear buenas prácticas de salud dirigidas a cada proceso de trabajo desempeñado en la institución.
\end{abstract}

DESCRIPTORES: Calidad de la atención de salud. Evaluación de servicios de salud. Seguridad del paciente. Enfermería. 


\section{INTRODUCTION}

\section{Quality and evaluation in the health services}

Quality emerges as a crucial factor for success in the health services. In this approach, quality and health can be understood as the obtaining of greater benefits over fewer risks for the patient/ client, which benefits are defined in terms of what is achievable in accordance with the resources available and the existing social values..$^{1-2}$

Quality, furthermore, is understood as meeting the needs of the service users, who must be heard, as much in relation to the systematic evaluation of the health professionals' attitudes, as regarding the impact of the processes offered to them. In this way, their evaluation can be undertaken through the technical performance which is configured as the application of the knowledge and technology in healthcare; and through the interpersonal relationship with the patient, in such a way as to meet ethical precepts, social norms, and these patients' legitimate expectations and needs. ${ }^{2-3}$

In this context, quality criteria can be adopted which serve as support for its checking, such as the Donabedian Model, which uses the following as its premises: Structure: that which involves the human, physical, material and financial resources, equipment, continuing education policies, and the establishing of care protocols; Process: that which corresponds to the set of activities in the production, in the health sector and in the relationships established between the professionals and the service users, including the search for diagnosis and the therapy used; and Result: this consists of the obtaining of the desirable characteristics of the products or services, depicting the effects of the care for the health of the patient and of the population, the cost measured, and whether this is compatible with the sustainability of the organization. $^{4}$

It is in all these dimensions and, more specifically, in the process to mention, that the care per se is established; it is in this interaction that the care, the improvement and the recovery occur. Nevertheless, shortcomings can appear, and, therefore, adverse events (AE) can occur. AEs can lead to unwanted complications, which compromise patient safety and which currently represent one of the biggest challenges for the improvement of quality in the health sector.

\section{Patient safety and safety culture}

The consolidation of patient safety is configured as support for proposals to improve quality, as its constructs allow the remodeling of the work processes, causing safe strategies to improve the health care.

Patient safety may be understood as the reduction, to an acceptable minimum, of the risk of unnecessary harm associated with healthcare. ${ }^{5}$

Inserted in this context is the safety culture, which is a critical component of quality in the health services. It may be understood as: "The safety culture of an organization is the product of individual and group values, attitudes, perceptions, competencies, and patterns of behavior that determine the commitment to, and the style and proficiency of, an organization's health and safety management. Organizations with a positive safety culture are characterized by communications founded on mutual trust, by shared perceptions of the importance of safety and by confidence in the efficacy of preventive measures" ${ }^{6: 18}$

Moreover, "The Safety Culture is configured based on five characteristics, operationalized by the organization's safety management: a) a culture in which all workers, including professionals involved in the care and managers, take responsibility for their own safety and for the safety of their colleagues, patients and family members; b) a culture which prioritizes safety above financial and operational goals; c) a culture which encourages and rewards the identification, notification and resolution of problems related to safety; d) a culture which, following the occurrence of incidents, promotes organizational learning; and e) a culture which provides resources, structure and responsibilization for the effective maintenance of safety". ${ }^{5}$

In the light of these considerations, studying the safety culture in the hospital raises the possibility of identifying the intervenient factors in the work process which impact on the patients' safety. The undertaking of research in the area makes it possible to discuss this culture, and the grasping of this knowledge leads to strengthening the effective communication of scientific evidence, techniques and recommendations aimed at ensuring patient safety in healthcare.

It is in this reflection that this study was undertaken, aiming to evaluate the perception of nursing professionals in a teaching hospital 
regarding the dimensions of patient safety culture, and to identify differences in perception of patient safety culture in the hospital's different units.

\section{METHOD}

This is a descriptive-exploratory study with a quantitative approach. It was undertaken in a hospital with 900 operational bed spaces, located in the municipality of São Paulo, in the state of São Paulo (SP), Brazil. It is characterized as a teaching hospital, as it has a Medical Residency and placements of students from secondary education an undergraduate and postgraduate levels, from various areas of healthcare.

The study population was made up of staff nurses, nursing technicians, and auxiliary nurses who work in the following units: Internal Medicine, Clinical Surgery, the Surgical Center, Pediatrics, Adult and Child Emergency Room, and the Adult and Pediatric Intensive Care Units. The following were adopted as exclusion criteria: professionals who had worked in the institution for less than one year; and those who were on leave, sick leave, and/or away from work when data collection took place. A total of 435 data collection instruments were distributed, of which 305 were returned.

The study followed the ethical precepts of National Health Council Resolution N. 196/96. It was approved by the Research Ethics Committee (REC) of the School of Nursing of the University of São Paulo and by the REC of the above-mentioned hospital, under protocols: (REC-EEUSP: N. 1070/2011) and (REC-Hospital: N. 083/11-V). The subjects' authorization occurred through the terms of free and informed consent.

The data were collected in February - June 2012, through the application of a questionnaire of the Agency for Healthcare Research and Quality (AHRQ), titled Hospital Survey on Patient Safety Culture (HSOPSC), translated into Portuguese and adapted from the original version in English.

In accordance with the AHRQ, ${ }^{7}$ safety culture, in all, has a total of 10 dimensions (Dimensions 1 to 10), although the AHRQ questionnaire presents two variables of results, which in this study were termed Dimensions 11 and 12 . The results section presents the dimensions and their definition.
The data collection instrument was constituted in two parts, the first with the sociodemographic variables, and the second made up of items which encompassed the dimensions of patient safety culture, the frequency of reports of adverse events, the degree of patient safety, and the number of events reported in the last year. This instrument can be answered by the multiprofessional healthcare team, the nursing team being selected in this study.

The instrument incorporates a Likert-type sociopsychological-technical scale, with a variation of 5 degrees of perception, ranging from "Strongly disagree" to "Strongly agree", and from "Never" to "Always".

After receiving the answered questionnaires, exclusion criteria were adopted in order to remove the invalid questionnaires. The criteria were similar to those instituted by the researchers ${ }^{7}$ who composed the original instrument: questionnaires which did not have at least one complete section; which had fewer than half of the items filled out; and which had the same response for all the items. A total of $301(n=301)$ questionnaires was selected as containing valid data for proceeding to a process of statistical analysis.

In order to test the questionnaire's reliability in relation to its internal consistency, the multivariate analysis alpha Cronbach statistical test was applied. Descriptive statistics were undertaken in relation to the analysis of the sociodemographic variables; the safety culture dimensions; and the degree of safety. Evaluations which were marked as agree/strongly agree or nearly always/always for the statements re-written in the affirmative form, and those marked as disagree/strongly disagree or rarely/never for the statements which were re-written negatively, were adopted as positive evaluations. For analysis purposes, scores from 1 to 5 were adopted, with 1 being the worst evaluation, and 5 the best.

In order to compare the means of the patient safety culture dimensions between the units, so as to identify whether there were statistically relevant differences, the ANOVA analysis of variance was applied. Complementing the ANOVA, the Tukey multiple comparison test was applied in order to identify pair-by-pair differences between the units. The level of significance adopted was 5\%. The R Program was used for calculating these statistics. ${ }^{8}$ 


\section{RESULTS}

Regarding the characterization of the research participants, the predominant age range was from 26 to 35 years old (57.2\%), and the majority were female $(74.5 \%)$. The majority educational level was senior high school completed (37.5\%). In relation to the participants' distribution in the units, the majority belonged to the Adult Intensive Care Unit (19.3\%), and the minority to the Child Emergency Room (3.3\%). The predominant role was auxiliary nurses (54.5\%), followed by nursing technicians (26.6\%) and nurses (18.9\%). Regarding time since graduation, the majority of participants (55\%) had graduated between 1 and 10 years previously, and in relation to time of work in the institution, the majority $(82.3 \%)$ had been working there for between 1 and 10 years.

Table 1 presents the questionnaire's dimensions; their definition; and the Cronbach a found in each one of the dimensions.

Table 1 - Distribution of the dimensions; their definition; and the results obtained through the application of the Alpha Cronbach test. São Paulo-SP, 2012

\begin{tabular}{|c|c|c|}
\hline Dimensions & Definition & $\alpha$ \\
\hline 1 Teamwork within units & $\begin{array}{l}\text { The workers support one another in the units, treat each other with re- } \\
\text { spect and work together as a team. }\end{array}$ & 0.68 \\
\hline $\begin{array}{l}2 \text { Supervisor/manager expecta- } \\
\text { tions and actions promoting pa- } \\
\text { tient safety }\end{array}$ & $\begin{array}{l}\text { Supervisors/managers consider the team's suggestions for improving } \\
\text { patient safety, praise the worker or team which follows procedures cor- } \\
\text { rectly, and do not neglect patient safety problems. }\end{array}$ & 0.77 \\
\hline $\begin{array}{l}3 \text { Organizational learning - con- } \\
\text { tinuous improvement }\end{array}$ & $\begin{array}{l}\text { There is a culture of learning, in which errors lead to positive changes, } \\
\text { and the changes' efficacy is evaluated. }\end{array}$ & 0.60 \\
\hline $\begin{array}{l}4 \text { Hospital management support } \\
\text { for patient safety }\end{array}$ & $\begin{array}{l}\text { Hospital management offers a work climate which promotes patient } \\
\text { safety and demonstrates that patient safety is the highest priority. }\end{array}$ & 0.72 \\
\hline $\begin{array}{l}5 \text { Feedback and communication } \\
\text { about error }\end{array}$ & $\begin{array}{l}\text { Staff are informed about errors which occur, feedback is provided } \\
\text { regarding changes implanted, and ways of preventing errors are dis- } \\
\text { cussed with the team. }\end{array}$ & 0.67 \\
\hline 6 Communication openness & $\begin{array}{l}\text { Staff can engage in discussion freely if they observe something which } \\
\text { could negatively affect the patient, and feel free to question their supe- } \\
\text { riors. }\end{array}$ & 0.63 \\
\hline $\begin{array}{l}7 \text { Teamwork across hospital } \\
\text { units }\end{array}$ & $\begin{array}{l}\text { The hospital's units cooperate and coordinate their activities so as to of- } \\
\text { fer the best care to the patient. }\end{array}$ & 0.56 \\
\hline 8 Staffing & $\begin{array}{l}\text { There are sufficient numbers of staff for the effective undertaking of the } \\
\text { work, and the number of hours worked is appropriate for offering the } \\
\text { best care to the patient. }\end{array}$ & 0.66 \\
\hline $\begin{array}{l}9 \text { Hospital handoffs and transi- } \\
\text { tions }\end{array}$ & $\begin{array}{l}\text { Important information regarding patient care is transmitted between } \\
\text { the hospital's units and during shift changes. }\end{array}$ & 0.70 \\
\hline $\begin{array}{l}10 \text { Nonpunitive response to er- } \\
\text { ror }\end{array}$ & $\begin{array}{l}\text { Staff feel that their mistakes and the events reported are not used against } \\
\text { them, and that mistakes they make are not kept in their personnel files. }\end{array}$ & 0.40 \\
\hline 11 Overall perceptions of safety & $\begin{array}{l}\text { The procedures and systems existent in the organization are effective in } \\
\text { presenting mistakes and there are no problems regarding patient safety. }\end{array}$ & 0.47 \\
\hline 12 Frequency of event reporting & $\begin{array}{l}\text { The frequency with which mistakes are notified in the various catego- } \\
\text { ries. }\end{array}$ & 0.87 \\
\hline
\end{tabular}

Figure 1 shows the distributions of the scores

ture dimensions. given by the participants to the patient safety cul- 


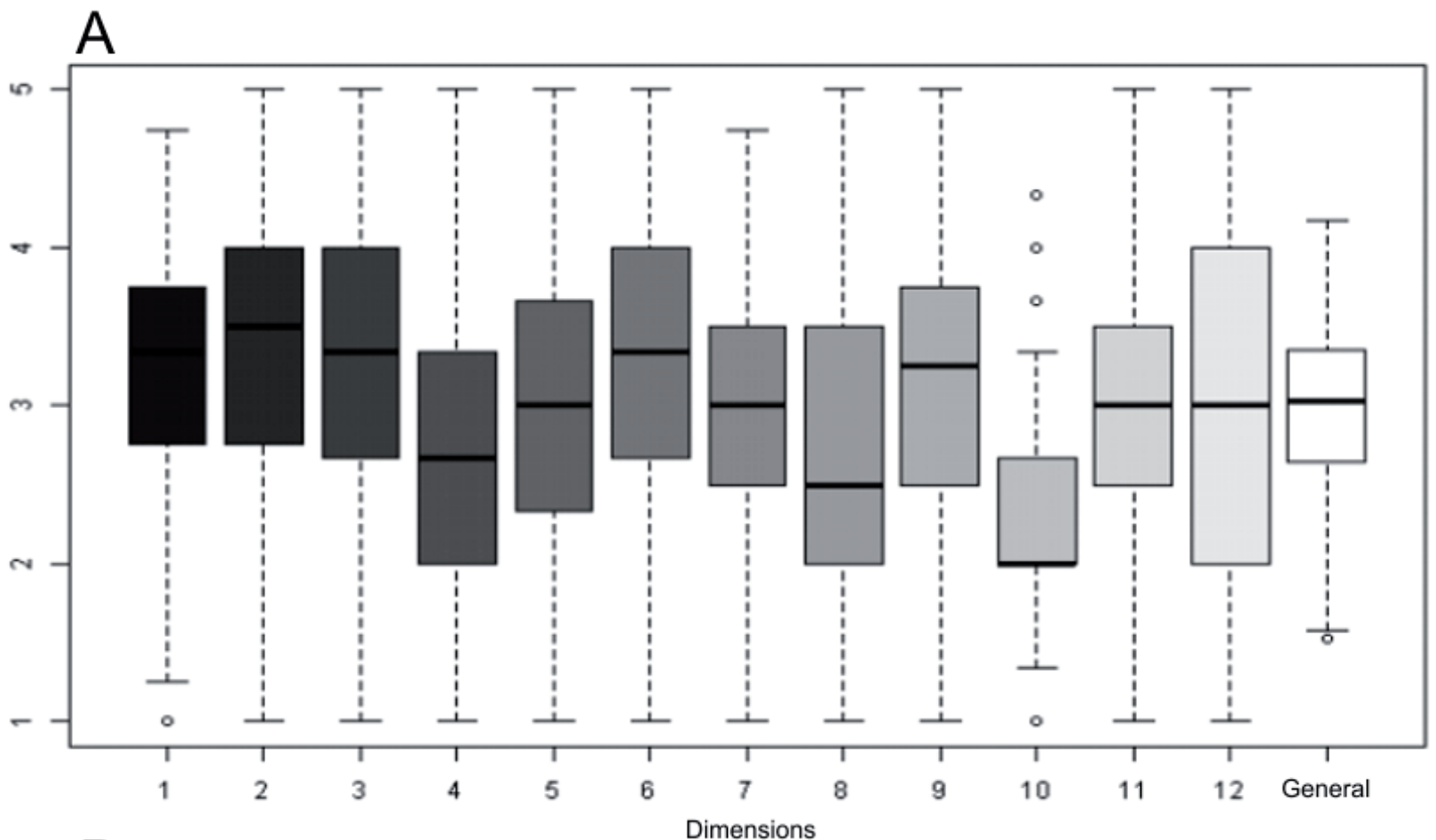

\begin{tabular}{|c|c|c|c|c|c|c|c|c|c|c|}
\hline \multirow[t]{2}{*}{ Score } & \multirow[t]{2}{*}{$\mathbf{N}$} & \multirow[t]{2}{*}{ Minimum } & \multirow[t]{2}{*}{ Maximum } & \multirow[t]{2}{*}{ Mean } & \multirow{2}{*}{$\begin{array}{l}\text { Standard } \\
\text { deviation }\end{array}$} & \multirow{2}{*}{ Median } & \multirow{2}{*}{$\begin{array}{c}\text { 1st } \\
\text { Quartile }\end{array}$} & \multirow{2}{*}{$\begin{array}{c}\text { 3rd } \\
\text { Quartile }\end{array}$} & \multicolumn{2}{|c|}{$\begin{array}{c}\text { CI for mean } \\
(95 \%)\end{array}$} \\
\hline & & & & & & & & & Inf & Sup \\
\hline Dimension 1 & 301 & 1.00 & 4.75 & 3.21 & 0.78 & 3.33 & 2.75 & 3.75 & 3.12 & 3.30 \\
\hline Dimension 2 & 296 & 1.00 & 5.00 & 3.32 & 0.89 & 3.50 & 2.75 & 4.00 & 3.22 & 3.43 \\
\hline Dimension 3 & 300 & 1.00 & 5.00 & 3.19 & 0.85 & 3.33 & 2.67 & 4.00 & 3.09 & 3.28 \\
\hline Dimension 4 & 299 & 1.00 & 5.00 & 2.73 & 0.92 & 2.67 & 2.00 & 3.33 & 2.63 & 2.84 \\
\hline Dimension 5 & 301 & 1.00 & 5.00 & 3.09 & 0.96 & 3.00 & 2.33 & 3.67 & 2.98 & 3.20 \\
\hline Dimension 6 & 301 & 1.00 & 5.00 & 3.32 & 0.92 & 3.33 & 2.67 & 4.00 & 3.21 & 3.42 \\
\hline Dimension 7 & 300 & 1.00 & 4.75 & 2.94 & 0.68 & 3.00 & 2.50 & 3.50 & 2.86 & 3.02 \\
\hline Dimension 8 & 301 & 1.00 & 5.00 & 2.70 & 0.90 & 2.50 & 2.00 & 3.50 & 2.60 & 2.80 \\
\hline Dimension 9 & 300 & 1.00 & 5.00 & 3.10 & 0.80 & 3.25 & 2.50 & 3.75 & 3.01 & 3.19 \\
\hline Dimension 10 & 301 & 1.00 & 4.33 & 2.29 & 0.71 & 2.00 & 2.00 & 2.67 & 2.21 & 2.37 \\
\hline Dimension 11 & 301 & 1.00 & 5.00 & 2.97 & 0.74 & 3.00 & 2.50 & 3.50 & 2.89 & 3.06 \\
\hline Dimension 12 & 298 & 1.00 & 5.00 & 3.06 & 1.25 & 3.00 & 2.00 & 4.00 & 2.92 & 3.20 \\
\hline General & 301 & 1.52 & 4.17 & 3.00 & 0.54 & 3.02 & 2.64 & 3.36 & 2.94 & 3.06 \\
\hline
\end{tabular}

Figure 1 - (A) Box Plot and (B) descriptive statistics representing the distribution of the dimensions' scores and general distribution of the questionnaire. Dimensions as explained in table 1. São PauloSP, 2012

Figure 2 presents the general score of the grouping of the dimensions by units of the hospital, and Figure 3 evidences the multiple com- parisons between the units researched with Tukey correction. 


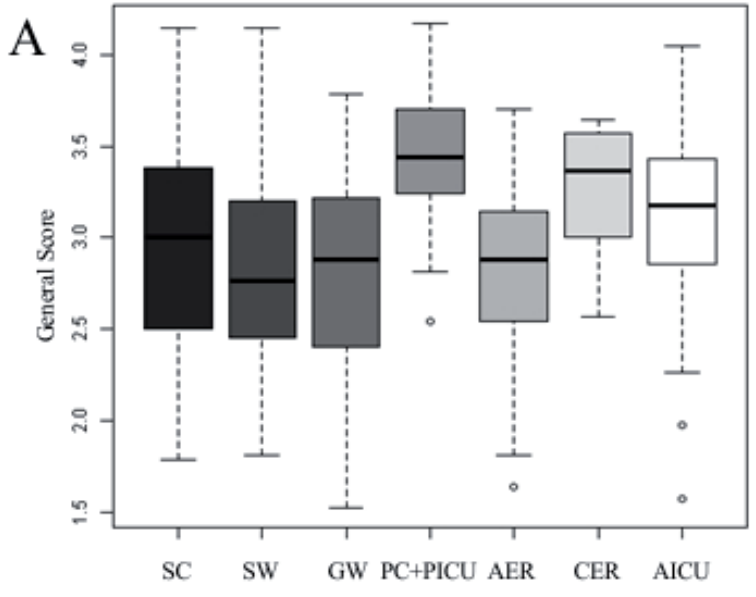

\begin{tabular}{lcccccccccc}
\hline \multicolumn{1}{c}{ Units } & N & Minimum & Maximum & Mean & $\begin{array}{c}\text { Standard } \\
\text { Deviation }\end{array}$ & Median & 1st & \multicolumn{2}{c}{ 3rd } & CI for Mean (95\%) \\
quartile & quartile & Inf & Sup \\
\hline Total & $\mathbf{3 0 1}$ & $\mathbf{1 . 5 2}$ & $\mathbf{4 . 1 7}$ & $\mathbf{3 . 0 0}$ & $\mathbf{0 . 5 4}$ & $\mathbf{3 . 0 2}$ & $\mathbf{2 . 6 4}$ & $\mathbf{3 . 3 6}$ & $\mathbf{2 . 9 4}$ & $\mathbf{3 . 0 6}$ \\
SC & 49 & 1.79 & 4.14 & 2.94 & 0.57 & 3.00 & 2.50 & 3.38 & 2.78 & 3.10 \\
SW & 43 & 1.81 & 4.14 & 2.84 & 0.56 & 2.76 & 2.45 & 3.20 & 2.67 & 3.01 \\
GW & 43 & 1.52 & 3.78 & 2.81 & 0.54 & 2.88 & 2.41 & 3.21 & 2.64 & 2.97 \\
PC+PICU & 43 & 2.55 & 4.17 & 3.43 & 0.38 & 3.44 & 3.24 & 3.70 & 3.31 & 3.55 \\
AER & 55 & 1.64 & 3.71 & 2.82 & 0.46 & 2.88 & 2.55 & 3.14 & 2.70 & 2.94 \\
CER & 10 & 2.57 & 3.64 & 3.24 & 0.38 & 3.37 & 3.03 & 3.54 & 2.96 & 3.51 \\
AICU & 58 & 1.57 & 4.05 & 3.12 & 0.51 & 3.18 & 2.86 & 3.42 & 2.99 & 3.26 \\
\hline
\end{tabular}

Figure 2 - (A) Box plot and (B) descriptive statistics representing the distribution of the scores of the patient safety culture among the units studied. Surgical Center (SC); Surgical Ward (SW); General Ward (GW); Pediatric Clinic and Pediatric Intensive Care Unit (PC+PICU); Adult Emergency Room (AER); Child Emergency Room (CER) and Adult Intensive Care Unit (AICU). São Paulo-SP, 2012

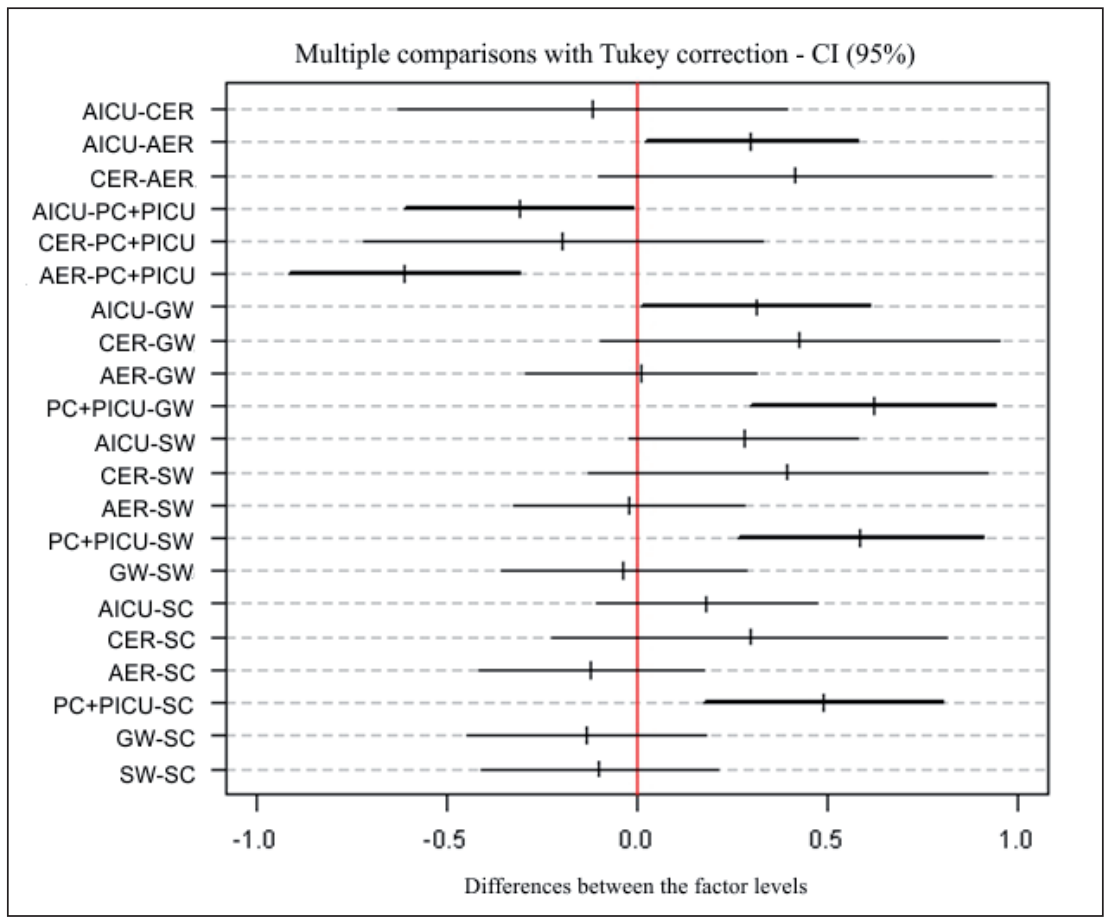

Figure 3 - Multiple comparisons between the units studied with Tukey correction. Surgical Center (SC); Surgical Ward (SW); General Ward (GW); Pediatric Clinic (PC) and Pediatric Intensive Care Unit (PC+PICU); Adult Emergency Room (AER); Child Emergency Room (CER) and the Adult Intensive Care Unit (AICU). São Paulo-SP, 2012 
Figure 4 describes the distribution of the by hospital unit. frequency of the degree of patient safety (DPS)

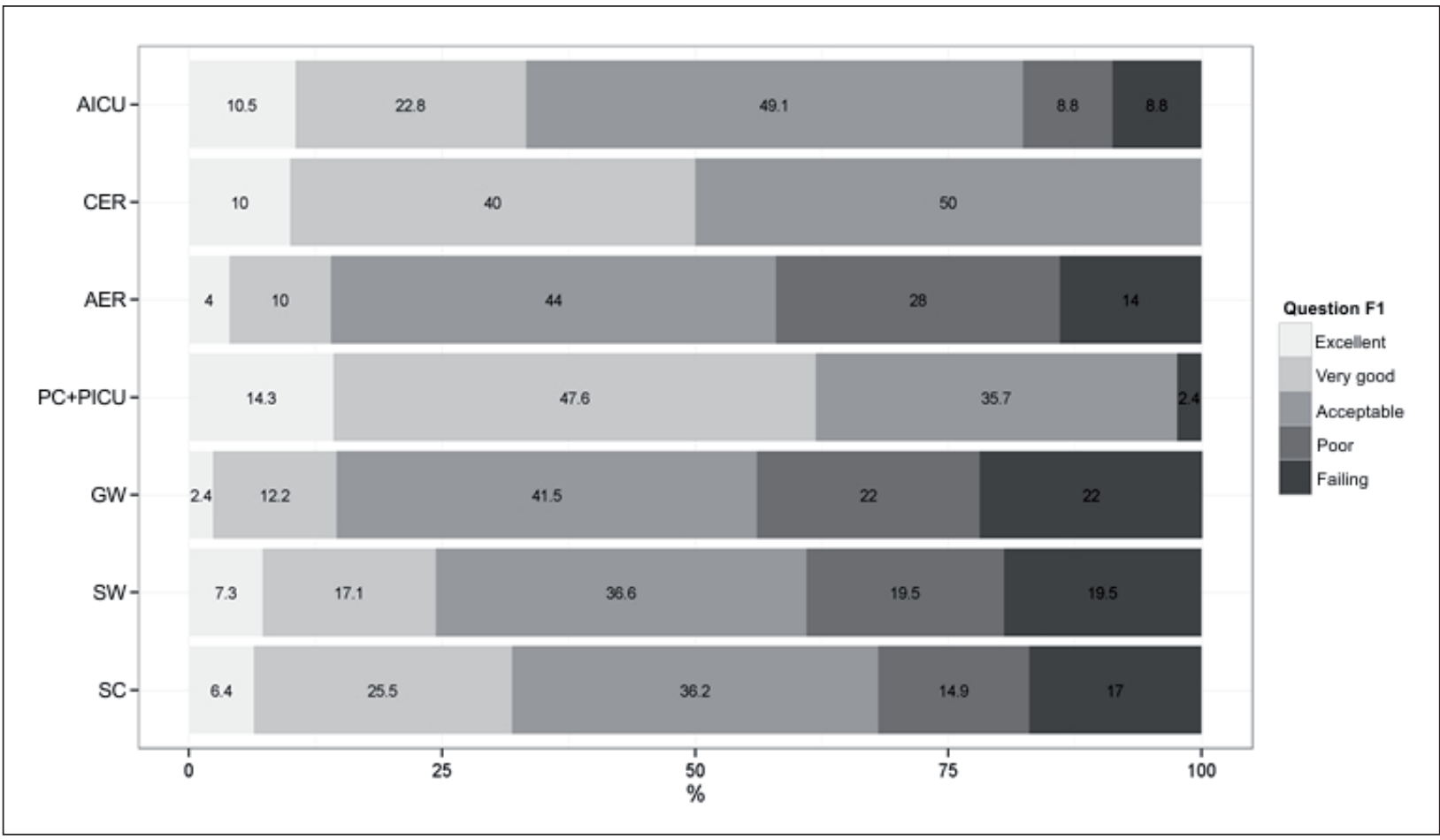

Figure 4 - Distribution of the Degree of Patient Safety (DPS) by unit studied. Surgical Center (SC); Surgical Ward (SW); General Ward (GW); Pediatric Clinic and Pediatric Intensive Care Unit (PC+PICU); Adult Emergency Room (AER); Child Emergency Room (CER) and Adult Intensive Care Unit (AICU). São Paulo-SP, 2012

\section{DISCUSSION}

\section{Reliability of the instrument}

In this study, the total Alpha Cronbach ( $a)$ was 0.90 , which confers high reliability on the questionnaire. The a varied from 0.40 to 0.87 for the dimensions. The questionnaire used has been widely used in studies in different countries,, ,9-10 in these studies, the a of the dimensions varied from 0.32 to 0.88 .

\section{Analysis of the distributions of the results by patient safety culture dimensions and general}

Based on Figure 1, it was observed that the dimensions with the best distributions were (2) Expectations and safety promotion actions of supervisors and managers, followed by (3) Organizational learning - continuing improvement and (6) Openness to communication. These data indicated that the majority of the participants believed that the supervisor/manager considered the team's suggestions for improving quality and did not neglect the problems related to patient safety. Moreover, they revealed that there was a culture of learning related to the adverse events and that the staff were able to engage in discussions if they observed something which was capable of negatively affecting the patient.

The worst distributions were in the following dimensions: (4) Support from hospital management for patient safety; (8) Staff and (10) Non-punitive responses to mistakes. These findings demonstrated that the majority of the staff perceived that the hospital management did not offer a work climate which promoted patient safety. They also revealed shortcomings in the dimensioning of staff and that the staff felt that their mistakes and the events reported could be used against them.

In relation to the general score, the mean was 3.00; the standard deviation was 0.54; the median was 3.02, with the $3^{\text {rd }}$ quartile corresponding to 3.36 . 
These data reveal a reasonable evaluation of the patient safety culture when the questionnaire is analyzed as a whole, revealing the general panorama of patient safety culture in the hospital's units.

\section{General score of the grouping of the dimensions by hospital unit}

Figure 2 represents the distribution of the scores of the dimensions of patient safety in the hospital's different units, based on which it was evidenced that the best evaluation was in the PC+PICU followed by the CER. The AICU presented a slightly better distribution than the GW and the AER. In addition to this, the GW, AER, SC and SW and SW had similar distributions.

In order to deepen the understanding in the distribution of the data, the ANOVA test of analysis of variance was applied. Based on this, it was possible to identify the existence of differences between the means of the units. After evidencing these differences, Tukey's correction was applied, which implemented multiple comparisons between means of the units.

Based on Tukey's Test, (Figure 3), it was possible to observe that the AICU presented scores which were better than those of the AER and GW - and, also, that the PC+PICU obtained better evaluations than the AICU, AER, GW, SW and SC. The test indicated that the units which worked with pediatric patients in the hospital had the best evaluations in relation to patient safety.

The differences evidenced may be multicausal. One of the inferences for explaining them may be in the work process undertaken in each scenario researched, as each unit has its specific character in relation to the dynamic of the work and they present the need for distinct decisionmaking, in addition to other factors which make up the work process, such as the number and quality of the staff and the patients, the workload, the continuing education, and the profile of each unit's management and leadership.

The work process in healthcare is constituted by work objects, which result from technical-social reductions in the reading of the health needs, which the different professionals' actions focus on, mediated by material and non-material instruments. The same integrates the specific processes of each area which makes up the health field, as each one constitutes, historically and socially, objects of intervention and instruments, in particular the knowledges, agents and specific aims. ${ }^{11}$
The evaluation in the various units made it possible to evidence that within a macro-context, such as in the large-size institution which was the scenario of this study, the various processes are outlined, and each service offered may be different, being based upon the quality evaluation constructs of the Donabedian Model, in which the units have different structures and specific processes and, therefore, results which are also differentiated.

These data make it possible to emphasize that programs and strategies aiming to improve quality in health institutions may have general proposals, but that they need to be suited to each work context and undertake changes in loco, with a view to responding to the specific characteristics of each department.

Moreover, the staff must take ownership of this knowledge in order to demand improvements which are specific to their unit; they must improve their practices; and seek to overcome their weak points. The professionals can reproduce and modify the work processes in which they are inserted through questioning the context they experience and through undertaking actions which transform the care provided. ${ }^{12}$

In relation to the pediatric units which presented the best results and which were shown to be the safest, it is reflected that the care in this department is influenced by a different work process and by the major impulse to changes in the care for the child admitted to hospital. As a result, the pediatric patient is seen as more than a biological Being. Pediatric care leads to the understanding of the impact of the process of hospitalization for the child/adolescent and her family, and the team exerts itself to provide more humanized and safe care.

In one study on pediatric patient care, the authors found recommendations addressing technical-scientific aspects such as: undertaking procedures with precision, responsibility and scientific knowledge; attention to the administration of drugs; the use of systematized protocols; and the notification of adverse events; they also, however, found aspects which emphasize interpersonal communication between the professional, patient and family; and provided evidence regarding the importance of play activities and the use of toys during the care. ${ }^{13}$

The data revealed a better evaluation of the safety culture in pediatric care. In the light of this result, it is reiterated that this care must be broadly discussed so as to consolidate still more advances, 
as pediatric patients are a high risk population, with specific physical and morphological characteristics differing from those of adults, and with complex cognitive, emotional and social development which can increase the chances of suffering some adverse event in the process of inpatient treatment. $^{14}$

The AICU was shown to be slightly better than other departments. In relation to this department, it is understood that it is a complex unit, with intense dynamism. These patients' seriousness and the constant oscillations in their state of health reinforce the importance of the existence of support structures for decision-making directed towards promoting safe care. ${ }^{15}$ This leads to an intense mobilization for the maximization of the safety of critically-ill patients and to varying initiatives which guide improvement; the study also reveals recommendations from the nursing staff to improve the safety culture in adult intensive care. ${ }^{16}$

In the above-mentioned research, ${ }^{16}$ the recommendations are based in the dimensions of safety culture. Suggestions were listed for improving procedures and work processes, such as: definition of protocols, risk barriers, patient identification, single dose medications and double checking. They also emphasized recommendations involving professional conduct, such as dedication, commitment and awareness at work, and respect and tenderness. In addition to this, suggestions emerged such as the creation of safety committees and encouragement to report mistakes and adverse events.

The AER, GW, SC and SW units obtained lower evaluative scores, and did not present significant differences between each other. The improvement of the quality of the care provided in these units is fundamental for the patients and for the maintaining of the appropriate functioning of the institution; emphasis is therefore placed on the need to support the mobilization with proposals aiming to change these scores and attack the intervening factors which reduce safety in these departments.

Moreover, the communication regarding aspects of patient safety culture which were evaluated better in the other units, in particular the pediatric units, must be shared interdepartmentally in the hospital. Understanding patient safety to be an aspect which must permeate the professionals' actions in all the institution's scenarios, from admission through to discharge, transfer or death, one must not lose sight of the fact that the success- ful experiences must be disseminated, divulging examples to be followed. The recommendations made clear in pediatric units and intensive care units can be adopted for the institution's other scenarios, respecting their specific characteristics and socializing the safe practices.

\section{The degree of patient safety by hospital unit}

Figure 4 evidences that the highest frequency of the classification of DPS as 'excellent' was in PC+PICU (14.3\%), and the lowest in GW $(2.4 \%)$. Classification as 'very good', also, was greater in PC+PICU (47.6\%), and lower in CER (10\%). In the majority of units, DPS was classified as 'Acceptable', which reveals a satisfactory DPS, although with potential for improvement. Regarding DPS classified as 'Poor', the units with the highest percentages were AER (28\%), GW (22\%) and SW $(19.5 \%)$, demonstrating that measures for strengthening patient safety must be implemented mainly in these areas. The GW, SW and SC were units with the highest percentages in the classification of DPS as Failing, with $22 \%, 19.5 \%$ and $17 \%$ respectively, demonstrating that, in these departments, the measures which aim for patient safety have not been efficacious.

\section{CONCLUSIONS}

The results in the dimensions and in the degree of patient safety evidenced that there were differences in the evaluations made by the institution's units. Emphasis is mainly placed on the units which treat pediatric patients, which presented the best scores. The importance of these findings is that they make it possible to outline more specific and fruitful models for improving quality. The evaluation of the contexts makes it possible to build good practices in health directed towards each work process performed in the institution.

We also reiterate that nursing, as a work practice, consolidated as an applied science, must encourage the interdepartmental exchanging of information, and conversation regarding the strategies which worked in the departments, in order to make the experience accessible to the other units.

Finally, taking the premises of the Donabedian Model as a basis, the aspects evidenced allow the improvement of the work process and the improvement of the safety of the care provided, to the extent that aspects related to the culture, to the process and consequently to the result can be remodeled. 
For the patient safety culture to be implemented positively, engagement is necessary on the political level, the strategic level, and the hospital's operational level, in an integrated mobilization, which involves the hospital management and the other staff.

\section{REFERENCES}

1. Donabedian A. The quality: how can it be assessed? JAMA. 1988 Sep; 260(12):1743-8.

2. Donabedian A. The role of outcomes in quality assessment and assurance. QRB Qual Rev Bull. 1992 Nov; 18(11):356-60.

3. Donabedian, A. The quality of medical care. Science. 1978 May; 200(4344):856-64.

4. Donabedian A. The definition of quality and approaches to its assessment: explorations in quality assessment and monitoring. Chicago (US): Health Administration Press; 1980.

5. Ministério da Saúde (BR). Portaria n. 529 de $1^{\circ}$ de abril de 2013: institui o Programa Nacional de Segurança do Paciente (PNSP). Brasília (DF): MS; 2013.

6. Nieva VF, Sorra J. Safety culture assessment: a tool for improving patient safety in healthcare organizations. Qual Saf Health Care. 2003; 12(Suppl 2):17-23.

7. Sorra JS, Nieva VF. Pilot study: reliability and validity of the hospital survey on patient safety [Internet]. In: Technical report prepared by Westat under Contract No. 290-96-004 Rockville, MD: Agency for Healthcare Research and Quality; 2004 [acesso 2011 Mai 22]. Disponível em: http://www.ahrq.gov/ professionals/quality-patient-safety/patientsafetyculture/hospital/userguide/hospcult.pdf

8. R Core Team. R: a language and environment for statistical computing [Internet]. Vienna (AU): R Foundation for Statistical Computing; 2012 [acesso
2012 Jul 18]. Disponível em: http://www.Rproject.org/

9. Massoco. ECP. Percepção da equipe de enfermagem de um hospital de ensino acerca da segurança do paciente [dissertação]. São Paulo (SP): Universidade de São Paulo, Programa de Pós-Graduação em Gerenciamento em Enfermagem; 2012.

10. Ito S, Kanato S, Kigawa M, Fujita S, Hasegawa T, Hasegawa T. Development and applicability of Hospital Survey on Patient Safety Culture (HSOPS) in Japan. BMC Health Serv Res [online]. 2011 Feb 7 [acesso 2012 Jul 20]; 11:28. Disponível em: http:// www.biomedcentral.com/1472-6963/11/28

11. Peduzzi M, Carvalho BG, Mandú ENT, Souza GC, Silva JAM. Trabalho em equipe na perspectiva da gerência de serviços de saúde: instrumentos para a construção da prática interprofissional. Physis. 2011; 21(2):629-46.

12. Oliveira EM, Spiri WC. O significado do processo de trabalho cuidar para o enfermeiro da UTI. Cienc Cuid Saúde. 2011; 10(3):482-89.

13. Santos JV, Santos KPB, Cardoso SC, Primo RNG, Barros LFNM. Segurança do paciente infantil no centro cirúrgico. Rev SOBECC. 2013 Jan-Mar; 18(1):44-53.

14. Porto TP, Rocha PK, Lessmann JC, Souza S, Kretzer $\mathrm{L}$, Anders JC. Identificação do paciente em unidade pediátrica: uma questão de segurança. Rev Soc Bras Enferm Ped. 2011 Dez; 11(2):67-74.

15. Sousa PAF, Dal Sasso GTM, DCC Barra. Contribuições dos registros eletrônicos para a segurança do paciente em terapia intensiva: uma revisão integrativa. Texto Contexto Enferm. 2012 Out-Dez; 21(4):971-9.

16. MelloJF, BarbosaSFF.Cultura desegurança dopaciente em terapia intensiva: recomendações da enfermagem. Texto Contexto Enferm [online]. 2013 Out-Dez [acesso 2014 Ago 26]; 22(4):1124-33. Disponível em: http:/ / www.scielo.br/scielo.php?script=sci_ arttext\&pid=S0104-07072013000400031 